\section{Arqueologia Amazônica}

\author{
Por Neil L. Whitehead \\ University of Wisconsin-Madison \\ (nlwhiteh@wisc.edu)
}
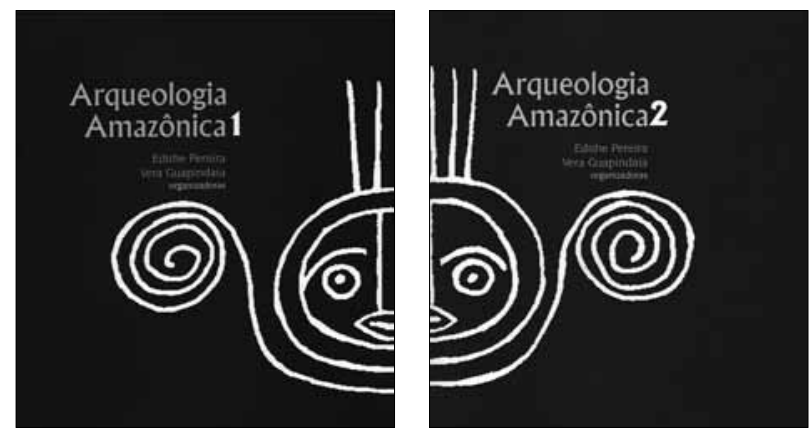

PEREIRA, Edithe: GUAPINDAIA, Vera (Orgs.). Arqueologia Amazônica. Belém: MPEG; IPHAN; SECULT, 2010. 1112 p. 2 v.: il. v. 1: ISBN 978 85-61377-21-2. v. 2: ISBN 978-85-61377-

22-9.

This is a wonderful collection that reflects the astonishing expansion of recent work on the archaeology of Amazonia. The editors, Edithe Pereira and Vera Guapindaia are to be warmly congratulated for having assembled such a valuable array of scholarship. The Museu Paraense Emilio Goeldi, as the editors make clear, is no less important in supporting the emergence of this two volume work and as such continues its tradition of pioneering archaeological research. Over the last two decades in particular there has been a steady growth of diverse theoretical and methodological approaches being brought to bear on an Amazonian past that transpires to be far richer and more complex, as well as more ancient, than earlier researchers had realized. The editors have also taken the laudable view that 'Amazonia' as a cultural and archaeological contrast is not to be strictly limited to the watershed defined by the Amazon River but must necessarily comprise the Orinoco River watershed, and the Guianas as well.
The first five chapters all look in various ways at human occupations sequences. Francisco Bocanegra examines the occupation of the tropical forests of Colombia to provide a regional synthesis of materials in the northwestern parts of the Amazonia. The date range is fairly wide, 7,000-3,000 BP and seems to be later than occupation of higher elevations to the west, such as Popayan, Bogotá or the coastal region of Urabá. At the 11,000 BP mark Maura Silveira and Denise Schaan discuss the occupation of the Atlantic coast during the Holocene era up to around 6,000-3,000 BP. Mariana Cabral and João Saldanha discuss the much later 'pre-colonial' sites and occupations for the State of Amapá to the north of the Amazon and a second chapter by Saldanha and Cabral goes on to consider new directions in expanding research about this very rich archaeological zone. Martijn van den Bel complements these chapters and extends discussion into the Guianas with a presentation of the result so an excavation of a Koriabo site on the Maroni River in French Guiana.

The discussion of Koriabo ceramics opens a wider regional perspective and Alberta Zucchi considers a broad model for the ancient migrations of the Maipuran Arawaks and the Caribs, while Franz Scaramelli and Kay Tarble, the late pre-Hispanic of the middle Orinoco through ceramic traces. Consideration of these kinds of archeological data is the basis for a chapter by Stéphen Rostain on the "myth or reality" of chieftains in the Guianas, although the review is useful it prompts the further question as to whether this debate itself is really helpful in understanding the archaeological materials since implicit and explicit in the earlier discussions are models of regional interaction that may have given rise to many political formations changing through time and thus only intermittently reflecting the kind of material markers of complexity that chiefdomtheorists hold significant. In the following chapter Cristiana Barreto uses the case of Marajó as a basis for reflecting on the wider relationships between ceramic production and social complexity. The themes of this discussion are

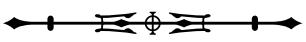


then taken up by Denise Gomes with regard to the famed ceramic art of Tapajó.

João Fonseca offers a fascinating discussion of lithic statuary from the lower Amazon first uncovered by João Barbosa Rodrigues in the nineteenth century and which have generally received less attention that these ceramic complexes. However, the thematic connections he suggests with the San Agustin complex in Colombia serve to remind us of the far flung connections that may have existed in ancient Amazonia. Edithe Pereira, Kay Tarble and Franz Scaramelli as well as Raoni Valle also consider lithic modeling in the form of 'rock art' or petroglyphic inscription and painting. Pereira offers some fascinating insights into the stylistic homologies between ceramic modeling of human figures and depictions in petroglyphs. This is an important departure in the interpretation of petroglyphs which have often been assumed to be pre-ceramic in character. Pereira shows convincingly that this homology merits much more thought and investigation. Tarble and Scaramelli's chapter definitively expands our appreciation of the richness and complexity of the petroglyphic repertoire for the Orinoco as does Valle for the Negro River. Taken together these three chapters really enhance our appreciation of the importance of placing 'rock art' in both a wider aesthetic frame and to seek the stylistic constancies that may well link these various local complexes into a wider panorama.

The final seven chapters of Volume I of this collection al deal with interesting and more recent methodologies with which to approach the past. Juliana Machado takes an ethno-archaeological approach to understanding the re-occupation of human cultural spaces which serves well to remind us that a theoretical bias towards initial and first forms of human activity can occlude the important ways in which continuous usage is less though about. Over some of the long time spans that are evident from the earlier materials in the volume is becomes very significant to ask how re-usage relates and changes materially our ability to understand initial and first occupations. In particular this bears strongly on such critical phenomenon such as the formation of terra preta (anthropogenic dark soils). Daniel Chocano and Marcos Magalhães in their separate chapters also employ ethno-archaeological techniques to better understand past anthropogenic process, both culturally as in Cochano discussion of cranial deformation, and with regard to ambient biotic life in Magalhães discussion of the 'natural' and 'anthropogenic' as categories through which to interpret contemporary biotic patterns. This theme is very nicely demonstrated also in Sheila Souza's discussion of the "bio-archaeological silence" in Amazonia, which very pertinently asks how the profound changes in human demography since 1500 are reflected in the presence and absence of tropical forest biota as reflected in the analysis of human bone materials. Ândrea Ribeiro-dos-Santos, Daniela Leite and Sidney Santos likewise consider the patterns of mitochondrial DNA that can be recovered from human remains as a way to map past human populations and their relatedness, also allowing them to draw out important contrasts not just between ancient populations but also between past and contemporary Amazonian demography.

The final two chapters of Volume I broach important if relatively unstudied features of archaeological work in Amazonia. Underwater archaeology is discussed by Gilson Rambelli who shows its many potentials. Unfortunately, as least in the Guyanese, this potential has already been shown through the mining and dredging operations carried out by gold-miners. Some of the most intriguing archaeological materials recovered have derived from the gold-dredges but are then obviously of little use for scientific interpretation. A more active program of underwater archaeology, as Rambelli shows, would therefore bring many benefits. Related to this accidental pillaging of archaeological materials is the question of tourism discussed by Shirlei Santos for the Rupununi region. A world-wide issue that necessarily asks us to balance 'science' and 'public access' is no less present, even if as yet fairly undeveloped, in Amazonia. Her essay is a welcome reflection on those themes and the role local communities themselves must take in managing their heritage. 
Volume II opens with a superb essay on archaeology and cultural memory by Michael Heckenberger. Focusing on late prehistoric occupations after $500 \mathrm{AD}$ the author very convincingly establishes the existence of "macro-regions". This insight matches work also done in the Orinoco Basin and takes Amazonian archaeology well beyond the very limited horizons of site-specific interpretations. This is a major step forward intellectually and allows, as the author notes, archaeological interpretation to be properly situated in larger "schema of historical and ecological change". Subsequent chapters by Eduardo Neves and Helena Lima likewise take up these themes in highly illuminating ways by examining both the nature of archaeological classifications in this light and the idea of a longue durée. Chapters by Lucas Bueno and Claide Moraes then undergird these approaches with specific discussion of lithic technology and chronologies of occupation as well as comparison of circular villages through time. These chapters in turn are nicely complemented by Anne Py-Daniel's discussion of funerary practices at the important Hatahara site in the Solimões River, Arkley Bandeira's discussion of fishing, gathering, hunting and ceramic production along the littoral regions at the mouth of Amazon River, allowing us to appreciate that there can be no simple one-to-one identification of ceramic production with 'settled agriculture'. A similar necessity for caution in applying developmental sequences derived from archaeology elsewhere is demonstrated in Maria Rodet, Vera Guapindaia and Amauri Matos's discussion of lithic and ceramic production more widely in Amazonia.

Gerard Migéon's discussion of the regional relations of the archaeological materials from French Guyana underlines the insights of the earlier chapters in these volumes by reminding us of the need to make interpretation spatially expansive and open to the possibility of relatively intensive regional interactions, in this case connecting the Caribbean to Amazonia. No less important is the chapter by Deusdédit Leite Filho that considers Maranhão and the cultural remains of populations that persisted into the historical era. Interpretation of such materials can have a significant impact on contemporary understandings of ethnicity and history, an issue which is then taken up extensively in the chapter by Fabíola Silva et al. reflecting on the theoretical implications of research, especially archaeological research, amongst extant indigenous populations. Both the subsequent chapters by Ana Galúcio and José Mazz also consider this important relation between ethnography and archaeology in the context of Matis and Tupi-Guarani populations.

The following chapters by Morgan Schmidt and by Manoel Arroyo-Kalin on anthrosoils formation, as well as Rita Scheel-Ybert et al. discussion of palaeoethnobotany, Albérico Queiroz and Olivia Carvalho's examination of zoo-archaeology and José Luiz's examination of geo-physical methodologies in the state of Pará, serve to remind us of the central place that these relatively new approaches to archaeological science hold in enabling the wider interpretations manifest in so many of the other chapters.

It is also very encouraging to see that the volume editors have not taken the narrow view that archaeology is only concerned with the ancient past, or at least the pre-colonial past and this is well validated by Marcos Albuquerque and Veleda Lucena's highly enlightening discussion of colonial fortifications and other built landscapes. Márcia Bezerra's chapter on education and cultural patrimony therefore is very welcome as national self-fashioning takes so many of its cues from how the archaeological past is made manifest through excavation and recovery of artifacts as well as the human landscape sin which such archaeological objects are situated. The concluding chapters to Volume II by Alicia Ebbitt on Belizean experiences with heritage education and Carla Carneiro's discussion of education about cultural patrimony therefore nicely round out the presentation of the various archaeological materials with timely reflection on what the purposes of archaeology itself may be and how to better direct them to constructive ends.

There are 44 separate chapters in the two volumes amounting to over 1000 pages and a minor criticism of 
the editorial strategy is that there is no thematic or topical grouping of the various contributions. Although this does not undermine the overall value of the volumes it leaves the reader (or reviewer) to wonder about the wider connections that could be inferred from the materials presented. Certainly overly-broad characterizations of this vast region would be premature, as the chapters themselves clearly demonstrate, but eventually it will become necessary even if to fracture the very category of 'Amazonia' itself. In the meanwhile the authors and especially editors are to be warmly congratulated on the production of such intellectually indispensable volumes. 